\title{
Catalisadores Metalocênicos: Aspectos Gerais e Heterogeneização.
}

\author{
Maria de Fátima V. Marques, Patricia Aragão C. J unior, Maria J osé C. Guimarães, Fernanda M. B. Coutinho
}

Resumo: Este trabalho apresenta uma discussão sobre aspectos gerais da nova tecnologia de síntese de polímeros com microestrutura e propriedades controladas, obtidos via sistema catalítico metaloceno/MAO. Mostra a importância da heterogeneização desses sistemas para possibilitar o seu emprego na produção industrial de uma ampla classe de materiais poliméricos. São discutidas ainda as principais características dos suportes mais empregados para esses catalisadores.

Palavras-chave: Sistema metaloceno/MAO; Suportes para catalisadores metalocênicos; Poliolefinas.

\section{Introdução}

Apesar de passados aproximadamente 40 anos desde a descoberta dos catalisadores Ziegler-Natta para polimerização, este campo da pesquisa continua apresentando grandes desafios. Seja nas indústrias ${ }^{[1]}$, universidades e centros de pesquisa, investe-se cada vez mais no estudo destes sistemas catalíticos. A constante busca de conhecimentos nesta área tem o objetivo de desvendar aspectos importantes que ainda não são completamente compreendidos, como a estrutura do sítio ativo e o mecanismo de polimerização. Obviamente para todo esse esforço existe uma justificativa mais prática: a cada ano cresce a demanda pelos polímeros produzidos via catálise Ziegler-Natta, especialmente poliolefinas, uma área bastante lucrativa que rende bilhões de dólares. As poliolefinas prometem substituir muitos outros materiais, desde elastômeros a termoplásticos, com a vantagem de facilitarem a reciclagem devido a menor multiplicidade de materiais no rejeito. Assim, é um objetivo geral dessa área da catálise a obtenção de sistemas catalíticos mais econômicos para a produção de polímeros já conhecidos e sistemas catalíticos novos para a produção dos mais variados materiais que poderão ter novas aplicações e, em conseqüência, novos mercados ${ }^{[2-5]}$.

A mais recente descoberta nessa área levou ao surgimento de uma nova geração de catalisadores Ziegler-Natta, que são os sistemas metaloceno/metilaluminoxano (MAO), reconhecidamente um dos principais avanços em ciência e tecnologia de polímeros das últimas décadas ${ }^{[6,7]}$, não só devido a alta eficiência desses sistemas, mas principalmente pela sua versatilidade e capacidade de produção de polímeros com propriedades não antes obtidas. A Tabela 1 mostra uma breve comparação ${ }^{[8-10]}$ entre as principais características dos polímeros obtidos via sistemas Ziegler-Natta convencionais de últimas gerações e via metaloceno/MAO.

Maria de Fátima V. Marques, Patricia Aragão C. Junior, Maria José C. Guimarães, Fernanda M. B. Coutinho- Instituto de Macromoléculas Prof. Eloisa Mano (IMA), Universidade Federal do Rio de Janeiro, C.P. 68525, CEP 21945-970, Rio de Janeiro, RJ 


\section{Sistemas Metalocênicos}

Os compostos metalocênicos são complexos organometálicos formados por um metal de transição dos grupos IV a VIII da Tabela Periódica, em geral zircônio, titânio ou háfnio, ligados a pelo menos um anel aromático tal como ciclopentadienila (Cp), indenila (Ind) ou fluorenila (Flu), substituído ou não, através de ligações do tipo $\pi$, formadas por um elétron do metal de transição e um elétron compartilhado por todos os átomos de carbono do anel $\left(\eta^{5}\right)$. Entretanto, para que esses complexos possam atuar como catalisadores, é necessário a presença de um cocatalisador. Os compostos metalocênicos têm sido estudados desde a década de 50 como catalisadores Ziegler-Natta ${ }^{[1]}$, apesar de muito pouco ativos para polimerização de etileno quando se emprega como cocatalisador um organo-alumínio simples como trietilalumínio (TEA). O interesse acadêmico por esse sistema deve-se ao fato de formarem sistemas homogêneos e, portanto, ser mais fácil identificar as espécies intermediárias para a proposição de um mecanismo de polimerização.

Somente nos anos 80 foi descoberto ${ }^{[17]}$ que os sistemas metaloceno/ $\mathrm{AlR}_{3}$ eram fortemente ativados por traços de umidade. Água, que sempre foi considerada um poderoso veneno para os catalisadores Ziegler-Natta, quando presente em quantidades mui-

Tabela 1: Sistemas catalíticos Ziegler-Natta: convencionais versus metalocênicos/MAO

\begin{tabular}{lcc}
\hline \multicolumn{1}{c}{ Característica } & $\begin{array}{c}\text { Catalisador } \\
\text { Ziegler-Natta } \\
\text { convencional }\end{array}$ & Sistema Metalocênico \\
\hline $\begin{array}{l}\text { Dispersão do } \\
\text { sistema catalítico } \\
\text { Metal de transição }\end{array}$ & Heterogêneo & Homogêneo \\
Cocatalisador & Alquilalumínio & $\begin{array}{c}\text { Aluminoxano ou ânions } \\
\text { não coordenantes [12,13] }\end{array}$ \\
Sítios ativos & Múltiplos & Idênticos \\
Monômeros & $\begin{array}{l}\text { Olefinas e } \\
\text { diolefinas }\end{array}$ & Olefinas* \\
$\begin{array}{l}\text { Distribuição de } \\
\text { comonômeros }\end{array}$ & Não uniforme & Uniforme \\
$\begin{array}{l}\text { Microestrutura dos } \\
\text { polímeros }\end{array}$ & Isotática, \\
Polidispersão & Largatictica, atática & Talhada sob medida \\
Teor de solúveis & Alto & Estreita \\
\hline
\end{tabular}

"potencialmente ${ }^{[14-16]}$ : cicloolefinas, estirênicos, diolefinas, monômeros polares.

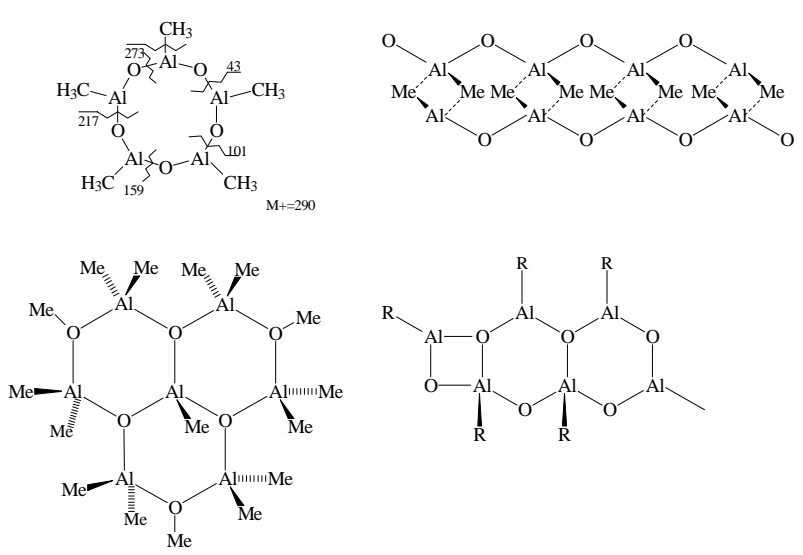

Figura 1. Algumas propostas ${ }^{[10]}$ para a estrutura MAO

to baixas causava um aumento surpreendente na velocidade de polimerização do etileno com sistemas do tipo dicloreto de diciclopentadienil-zircônio $\left(\mathrm{Cp}_{2} \mathrm{ZrCl}_{2}\right) / \mathrm{AlMe}_{3}$. A suspeita de que $\mathrm{AlMe}_{3}$ era hidrolisado com formação de metil-aluminoxano (MAO) foi confirmada, sendo o MAO caracterizado como uma mistura de oligômeros de composição aproximada $(-\mathrm{Al}(\mathrm{Me}) \mathrm{O}-)_{\mathrm{n}}$. Foi mostrado ainda que o MAO é bem mais efetivo como cocatalisador que outros aluminoxanos como etil-aluminoxano (EAO) ou isobutil-aluminoxano (IBAO) ${ }^{[17]}$. Esse composto constitui agora um novo e intrigante mistério na área de catálise Ziegler-Natta. Sua composição, estrutura e até seu papel como cocatalisador ${ }^{[10,18]}$ não foram ainda completamente esclarecidos. A hidrólise de $\mathrm{AlMe}_{3}$, uma reação extremamente exotérmica e potencialmente perigosa, é conduzida em condições controladas e parece gerar oligômeros do tipo $\mathrm{M}_{2} \mathrm{Al}-(\mathrm{OAlMe})_{\mathrm{n}}-\mathrm{OAlMe}_{2}$, onde $n$ pode variar de 5 a 28 e depende do método de síntese do MAO. Os problemas que surgem quando se analisa a estrutura do MAO advêm do caráter dinâmico do equilíbrio entre oligômeros lineares, cíclicos e ramificados. O resíduo de $\mathrm{AlMe}_{3}$ que permanece em soluções de MAO parece participar do equilíbrio de interconversão dos diferentes oligômeros de MAO (Figura 1) ${ }^{[10]}$.

\section{0 sítio ativo}

O modo como o MAO ativa o complexo metalocênico para formar o sistema catalítico é uma questão que já tem a concordância de muitos pesquisadores: o composto metalocênico (Ex.: $\left.\mathrm{Cp}_{2} \mathrm{ZrCl}_{2}\right)$ é alquilado pelo MAO $\left[\mathrm{Cp}_{2} \mathrm{Zr}\left(\mathrm{CH}_{3}\right)_{2}\right]$ que, em excesso, abstrai um íon $\mathrm{CH}_{3}{ }^{-}$formando espécies iônicas do tipo $\left[\mathrm{Cp}_{2} \mathrm{Zr}\left(\mathrm{CH}_{3}\right)\right]^{+}$cujo contra-íon pode ser ge- 


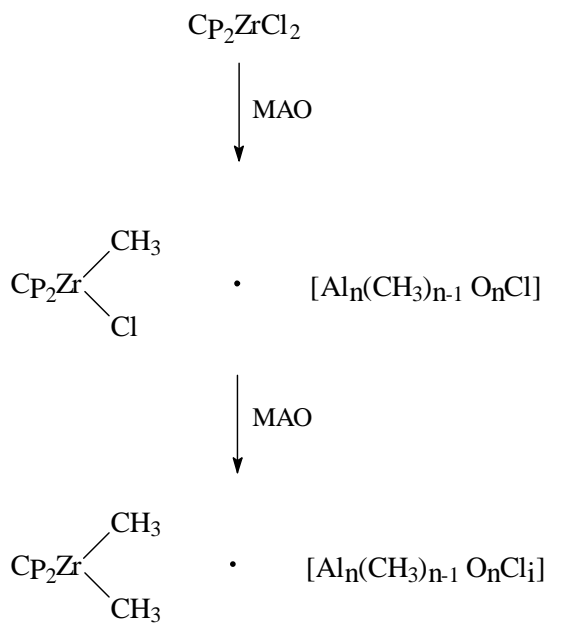<smiles>C[Al](C)O[Al](C)O[Al](C)C</smiles><smiles>C[14C](=[18O])O[Al](C)O[14CH3]</smiles>

ou

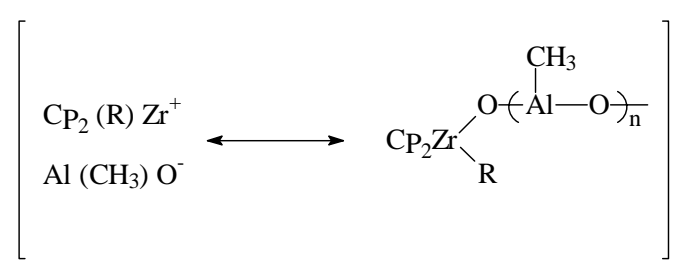

Esquema 1. Formação da espécie ativa ${ }^{[10]}$ nos sistemas metaloceno/MAO

nericamente representado por $\mathrm{MAO}^{-},\left[\mathrm{CH}_{3}-\mathrm{MAO}\right]^{-}$ou $\mathrm{Al}\left(\mathrm{CH}_{3}\right) \mathrm{O}^{-}$(Esquema 1$)^{[10]}$.

O primeiro passo do mecanismo de polimerização é a coordenação da olefina no orbital vazio do átomo do metal de transição ${ }^{[19]}$. O contra-íon $\mathrm{MAO}^{-}$deve estar o mais afastado possível da espécie catiônica para facilitar a coordenação do monômero e aumentar a velocidade de polimerização. A inserção do monômero ocorre entre a ligação metal de transiçãocarbono da espécie deficiente de elétrons $\left[\mathrm{Cp}_{2} \mathrm{Zr}-\right.$ $\left.\left(\mathrm{CH}_{3}\right)\right]^{+}$, que é o intermediário da catálise homogênea de polimerização ${ }^{[20]}$. A nova inserção de monômero ocorrerá então no sítio de coordenação oposto ao sítio inicialmente vago (Figura 2). A terminação da cadeia ocorre por transferência de hidrogênio do carbono $\beta$ para o metal de transição e a cadeia

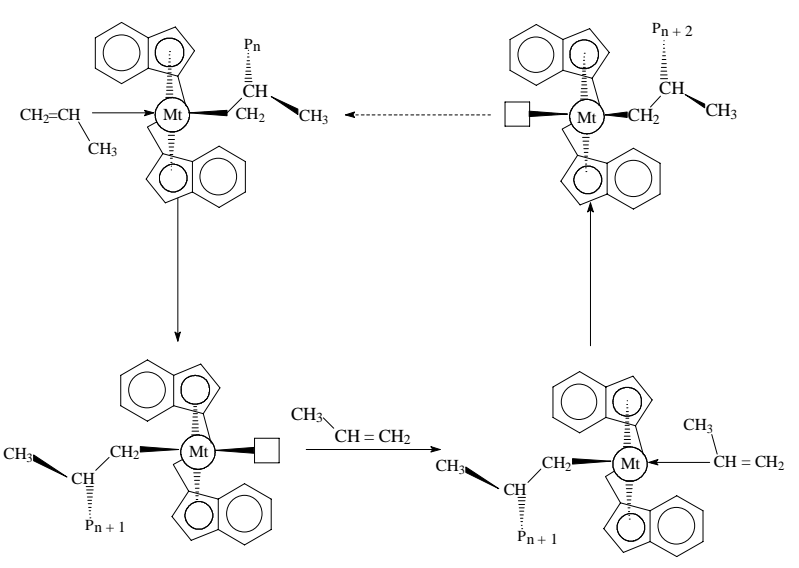

Figura 2.Mecanismos de Polimerização via sistema metaloceno/MAO ${ }^{[8]}$

polimérica contém uma insaturação terminal. O sítio catalítico pode reiniciar uma nova cadeia de polímero pela inserção de monômero entre a ligação Mt-H.

$\mathrm{O}$ sistema metalocênico se torna cataliticamente ativo apenas quando a concentração de MAO atinge razões Al/Zr superiores a cerca de 200 e aumenta acentuadamente com o aumento da quantidade de MAO no meio reacional. Valores de razão $\mathrm{Al} / \mathrm{Zr}$ de até 100.000 já foram reportados na literatura ${ }^{[19]}$. A explicação para a necessidade de concentrações tão elevadas de MAO é ainda assunto de muita discussão. Inúmeros papéis ${ }^{[21,22]}$ são atribuídos ao MAO no curso da polimerização:

- O primeiro deles é como agente alquilante do metal de transição.

- $\mathrm{O}$ segundo é como agente abstrator de $\mathrm{CH}_{3}{ }^{-}$do complexo alquilado, levando à formação das espécies catiônicas que são estabilizadas pelo contra-íon $\left[\mathrm{CH}_{3}-\mathrm{MAO}\right]^{-}$, através de uma coordenação fraca, o bastante, para permitir que o monômero desloque o contra-íon do sítio de coordenação do metal de transição e seja inserido entre a ligação metal de transição-carbono (Mt-C).

- Uma vez formado o sítio ativo pelo excesso de MAO, começa a ocorrer lentamente uma reação secundária de desativação bimolecular ${ }^{[23]}$, que o converte em uma espécie temporariamente inativa, mas que pode ser reconvertida em espécie ativa através da reação com excesso de MAO. Uma outra reação, ainda mais lenta, converte essa espécie inativa temporária em outra definitivamente inativa (Esquema 2).

- Agente capturador de impurezas

- Alguns autores ${ }^{[24,25]}$ atribuem a estabilização da espécie ativa à formação de um complexo tipo coroa entre MAO e o cátion metalocênico. 


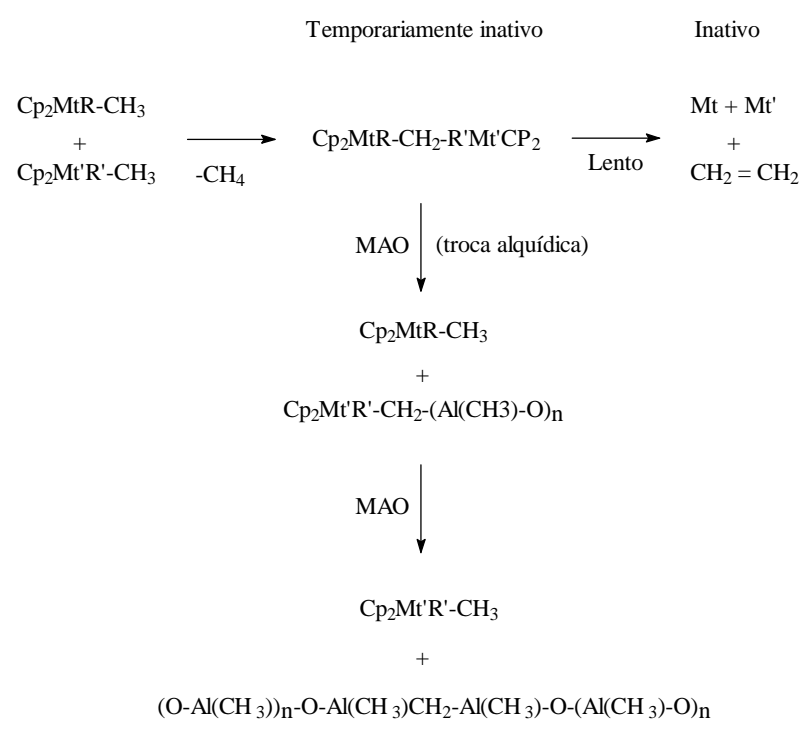

Esquema 2. Reações de desativação da espécie ativa do sistema metaloceno/MAO ${ }^{[23]}$

- Na literatura ${ }^{[10]}$ foi descrita a formação de uma estrutura tridimensional composta por uma ou várias moléculas de $\mathrm{MAO}$, que seria a responsável pelo papel de cocatalisador.

Um aspecto importante que diferencia os sistemas metalocênicos dos catalisadores Ziegler-Natta convencionais é o fato de os polímeros produzidos pelos primeiros apresentarem distribuição de peso molecular estreita $(\mathrm{Mw} / \mathrm{Mn} \approx 2$ ), enquanto que os últimos produzem polímeros com polidispersão larga $(\mathrm{Mw} / \mathrm{Mn}$ $\approx 5-10$ ). Uma polidispersão igual a 2 significa que as cadeias poliméricas são formadas por sítios catalíticos idênticos, uma vez que todos os sítios possuem a mesma razão entre as constantes de propagação e de transferência de cadeia, $\mathrm{k}_{\mathrm{p}} / \mathrm{k}_{\mathrm{t}}^{[23]}$. A característica de sítio ativo único dos sistemas metalocênicos confere aos polímeros produzidos uma grande regularidade, não só em termos de distribuição de peso molecular, como também na microestrutura das cadeias, no tamanho das ramificações, na freqüência das inversões durante a inserção do monômero e, no caso de copolimerizações, uma estreita distribuição de composições entre as cadeias poliméricas do produto obtido ${ }^{[26]}$. Nos casos em que a aplicação do polímero requer uma distribuição de peso molecular mais larga pode-se empregar misturas de catalisadores metalocênicos ${ }^{[27]}$.

\section{Controle da Microestrutura}

Somente a partir dos anos 84/85, com a descoberta dos primeiros complexos metalocênicos homogêneos capazes de polimerizar propileno ou outras
Isotático

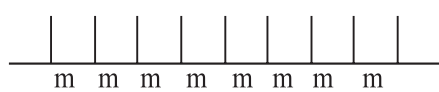

Sindiotático

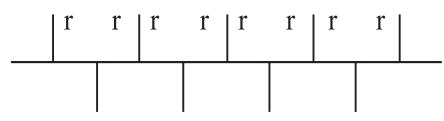

Hemi-istotático

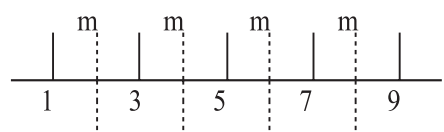

Atático

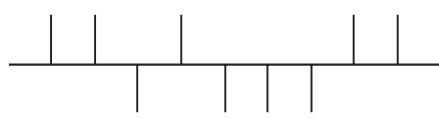

Isoblocos

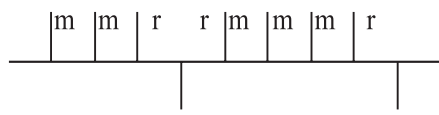

Estereoblocos

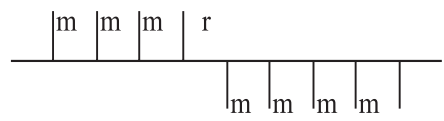

Figura 3. Algumas configurações possíveis para as cadeias de polipropileno $^{[7]}$

$\alpha$-olefinas pró-quirais com alta estereorregularidade isotática $^{[28]}$ é que o interesse nessa área explodiu. Esses complexos catalíticos são compostos quirais, porém a quiralidade é uma condição necessária mas não suficiente quando se deseja alta isoespecificidade.

Através da seleção apropriada de um complexo metalocênico precursor é possível produzir, por exemplo, polipropileno com diferentes microestruturas $^{[29-31]}$ (conseqüentemente, com as mais variadas propriedades): cadeias com configurações isotática, sindiotática, hemi-isotática, atática ou estereoblocos isotáticos, podem ser sintetizadas controladamente (Figura 3) $^{[21]}$.

Um complexo metalocênico quiral contendo dois ligantes idênticos tem simetria C2 (girandose esse composto por um ângulo $360^{\circ} / 2$, isto é $180^{\circ}$, a mesma simetria é obtida) e, portanto, os dois sítios de coordenação são equivalentes ${ }^{[32]}$, de forma que a inserção de olefina na ligação Mt-C ocorrerá preferencialmente pela mesma face monomérica (ré ou si) em ambos os sítios (sítios homotópicos). O mecanismo de controle da inserção de monômero ocorre através do sítio enanciomórfico (enantiomorphic-site control). Conseqüentemente, um complexo metalocênico tem que ser quiral e possuir simetria $\mathrm{C} 2$ para se obter um catalisador altamente isoespecífico.

A Figura 4 mostra um exemplo clássico de um complexo metalocênico ${ }^{[33]}$ que se isomeriza reversi- 


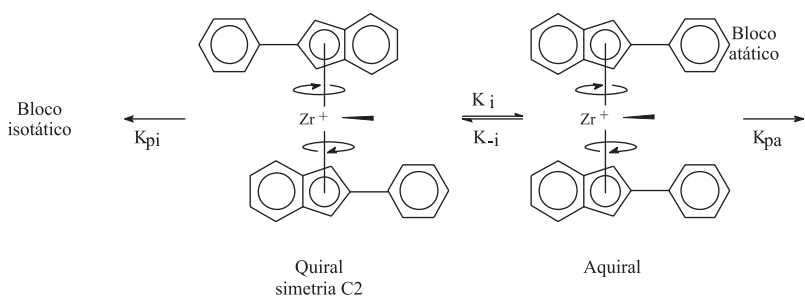

Figura 4. Complexo metalocênico com rotação entre os ligantes; catalisadores oscilantes ${ }^{[23,33]}$

velmente entre as geometrias quiral (com simetria C2) e aquiral, por rotação dos ligantes em torno dos eixos de coordenação com o metal de transição. O polipropileno obtido com esse sistema catalítico possui cadeias constituídas por blocos isotáticos e atáticos alternados, o que confere propriedades elastoméricas aos produtos obtidos. $\mathrm{O}$ tamanho desses blocos pode ser regulado através da variação da temperatura de polimerização. Para maior restrição na velocidade de isomerização são necessários substituintes mais volumosos nos anéis ligantes.

Uma ponte (Ex.: $\mathrm{CH}_{2}<;-\mathrm{CH}_{2}-\mathrm{CH}_{2}-;\left(\mathrm{CH}_{3}\right)_{2} \mathrm{Si}<$; $\left.\left(\mathrm{CH}_{3}\right)_{2} \mathrm{C}<\right)$ entre os anéis ligantes impõe uma estereorrigidez ao complexo metalocênico (esses compostos com ponte são chamados ansametalocenos), impedindo a rotação livre dos ligantes em torno de seus eixos de coordenação. Dessa forma, o arranjo espacial das espécies isoméricas ${ }^{[34,35]}$ racêmicas (formas $d$ e $l$ ) quirais é mantido e o polímero produzido possui configuração altamente isotática. No caso do emprego de complexos metalocênicos da forma isomérica meso como catalisador, as duas orientações para o monômero são igualmente favorecidas e, portanto, polímero atático é produzido (Figura 5) ${ }^{[33]}$. Dependendo do método de síntese dos compostos metalocênicos, a mistura racêmica pode ser obtida em alta proporção, sendo a concentração da forma meso muito baixa.

Para se obter um polímero com configuração altamente sindiotática, o complexo metalocênico precursor deve possuir simetria Cs (simetria de plano, isto é cor-

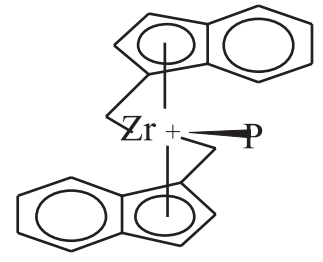

Racêmica

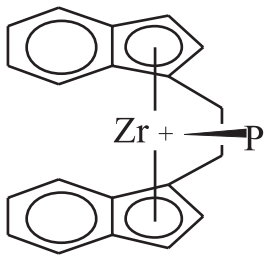

Meso
Figura 5. Formas isoméricas de catalisadores metalocênicos quirais ${ }^{[33]}$

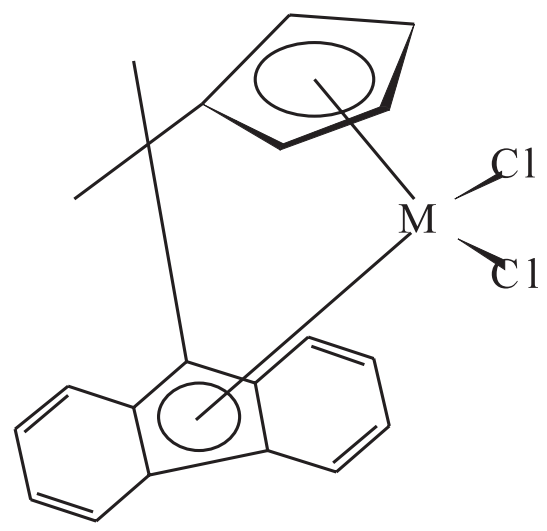

Figura 6. Estrutura de complexo metalocênico com simetria $\mathrm{Cs}^{[32]}$

tando-se o complexo metalocênico por um plano, temse duas porções idênticas), com um ligante não substituído e outro igualmente substituído dos dois lados do anel aromático (Figura 6) ${ }^{[32]}$. Neste caso, o monômero se insere alternadamente com uma face diferente, uma vez que os dois sítios de coordenação são enanciotópicos, isto é, cada inserção de monômero tem que ocorrer num sítio de coordenação oposto ao anterior. Se for realizada uma substituição em um dos ligantes na estrutura do composto metalocênico do exemplo anterior, a simetria Cs é perdida (o complexo passa a possuir, então, simetria $\mathrm{C} 1$, ou seja, é assimétrico) e a orientação do monômero não é mais controlada em um dos sítios de coordenação. O resultado é a formação de um polímero com configuração hemi-isotática ${ }^{[23,36]}$.

Durante a síntese de polímero estereorregular podem ocorrer defeitos ocasionais de inserção de monômero. Assim, durante a síntese de, por exemplo, polipropileno isotático com catalisador quiral com simetria $\mathrm{C} 2$, pode haver a incorporação de uma unidade monomérica de configuração invertida. A incorporação da unidade monomérica seguinte deve ocorrer pelo controle do sítio enanciomórfico (Figura 7a). No caso de catalisador aquiral (Ex.: $\mathrm{Cp}_{2} \mathrm{TiPh}_{2} /$ $\mathrm{MAO}$ ), onde a estereorregularidade parcialmente isotática, obtida a baixas temperaturas, é ditada pela configuração do centro assimétrico da última unidade monomérica inserida, defeitos de inserção monomérica tendem a se perpetuar ao longo da cadeia polimérica (controle pelo final da cadeia) (chainend control) (Figura 7b) gerando estruturas completamente diferentes ${ }^{[21,23]}$ daquelas preditas pelo mecanismo de controle do sítio. Um defeito secundário de encadeamento de unidades monoméricas ocorre pela adição 2,1 , que leva à formação de uma estrutura com dois carbonos terciários adjacentes (regiosseletividade). 


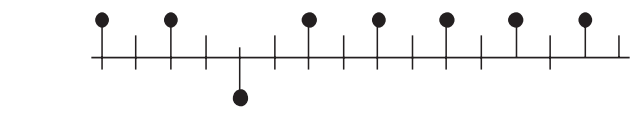

a) Controle pelo sítio enanciomórfico

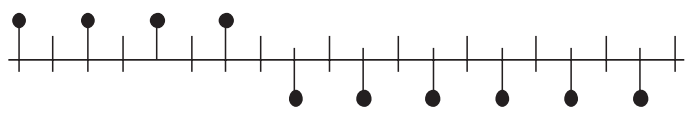

b) Controle pelo final da cadeia

Figura 7. Microestrutura de polipropileno obtidas (a) por controle pelo sítio enanciomórfico e (b) por controle final da cadeia ${ }^{[21]}$

Em suma, pequenas mudanças na estrutura do complexo metalocênico, quer pela introdução de grupos substituintes nos ligantes quer na ponte, podem produzir resultados surpreendentes em termos de variação da atividade catalítica ou da microestrutura, peso molecular e polidispersão do produto obtido ${ }^{[37,38]}$.

\section{Catalisadores metalocênicos suportados}

O fato de os catalisadores metalocênicos serem sistemas homogêneos faz com que apresentem inúmeros inconvenientes que limitam seu emprego nos processos de produção de poliolefinas. $\mathrm{O}$ primeiro deles reflete todos os inconvenientes de uma polimerização em solução, isto é, requer o uso de grandes quantidades de solvente e a morfologia do polímero produzido não é controlada. O polímero é obtido sob a forma de pó fino, que resulta não só num aumento de viscosidade, mas que causa o fenômeno de "fouling", produzindo um material aglomerado nas paredes do reator ${ }^{[39]}$ que pode inutilizá-lo. A necessidade de altas razões cocatalisador/composto metaloceno para formar o complexo catalítico com alta atividade é um obstáculo econômico além de deixar resíduos de alumínio no polímero ${ }^{[40]}$, que torna necessária a introdução de uma etapa de purificação no processo de produção.

Talvez a mais importante restrição para o emprego desses sistemas catalíticos homogêneos seja o fato das plantas industriais em operação empregarem processos de polimerização mais modernos como em fase gasosa ou em lama, através do uso de catalisadores Ziegler-Natta heterogêneos. A substituição desses catalisadores de $3^{\mathrm{a}}$ e $4^{\mathrm{a}}$ gerações por catalisadores metalocênicos seria mais conveniente se as mesmas plantas industriais pudessem utilizar esses novos sistemas catalíticos sem maiores modificações ${ }^{[41]}$.

Um dos métodos mais estudados nos últimos anos pelos grupos de pesquisa e principalmente por gran- des empresas para superar essas limitações é a imobilização dos catalisadores em suportes adequados. O que se espera é que a imobilização do complexo metalocênico venha a diminuir os processos de desativação bimolecular e que se obtenha sítios ativos mais estabilizados. A pesquisa que vem sendo realizada por diversos grupos tem demonstrado, porém, o desafio que é o desenvolvimento de catalisadores metalocênicos heterogeneizados sem perda de atividade em relação ao catalisador homogêneo precursor e ainda com as mesmas propriedades desses últimos, isto é, com o mesmo controle estereoquímico e habilidade para produzir polímero com a mesma uniformidade. A escolha apropriada de um suporte catalítico deve favorecer também a obtenção de partículas de polímero com o tamanho e forma próximas às normalmente obtidas nos grânulos do produto após peletização. As características do suporte devem ser transferidas para as partículas de polímero pelo fenômeno de réplica ${ }^{[42]}$.

\section{Processos de incorporação de catalisadores metalocênicos na superfície do suporte}

Quando duas fases imiscíveis são postas em contato, sempre ocorre que a concentração de uma substância numa fase é maior na interface do que no seu interior. A essa tendência de acumulação de uma substância sobre a superfície de outra dá-se o nome de adsorção. O processo de adsorção é espontâneo e ocorre, por que os átomos de qualquer superfície não possuem as forças de atração perpendiculares ao seu plano balanceadas e, portanto, apresentam certo grau de insaturação. Costuma-se distinguir dois tipos de adsorção: a adsorção física ou fisissorção e a química ou quimissorção. A fisissorção se caracteriza por um baixo grau de interação entre o adsorvido e o suporte (as forças envolvidas são da mesma ordem de grandeza das forças de Van der Waals), o equilíbrio é atingido rapidamente e é reversível. A quimissorção, ao contrário, se caracteriza por um forte grau de interação entre as moléculas, onde o adsorbato geralmente sofre uma mudança química. A quimissorção é um fenômeno irreversível altamente seletivo, uma vez que a reação química ocorre apenas em sítios específicos do suporte. A quimissorção necessita de temperaturas bem maiores que a fisissorção.

A heterogeneização dos catalisadores metalocênicos pode ser efetuada basicamente através dos 
dois métodos de adsorção citados. A quimissorção dos vários compostos relacionados com o sistema metalocênico é, porém, o método mais amplamente empregado, especialmente para polimerizações em lama. As formas mais comumente empregadas de adsorção são:

\section{Quimissorção do composto metalocênico}

Esse processo envolve a reação direta entre uma solução contendo o complexo metalocênico e o suporte sólido a temperaturas altas. É o processo mais simples, mas apresenta como inconveniente a possibilidade de ocorrer reações de desativação do catalisador metalocênico potencialmente ativo (formação de composto de zircônio não ativável pela adição de cocatalisador ou mesmo decomposição do complexo metalocênico com eliminação dos ligantes ${ }^{[43]}$ ) com sítios específicos da superfície do suporte. Assim, por exemplo, interações com os sítios ácidos de Brönsted $(\mathrm{OH})$ da superfície do suporte são acompanhadas de desprendimento de hidrocarbonetos ou de moléculas de $\mathrm{HCl}$, dependendo da estrutura do metaloceno empregado. Já os sítios ácidos de Lewis favorecem a formação de espécies catiônicas. Portanto, diferentes sítios podem promover a formação de espécies de natureza e atividade quimicamente diferentes das do complexo original.

Quimissorção de alquilalumínio ou MAO e posteriormente do composto metalocênico

Com o objetivo de diminuir a desativação do precursor catalítico na superfície do suporte, alguns pesquisadores $^{[25,41,43]}$ optaram por realizar um pré-tratamento do suporte com compostos do tipo alquilalumínio (TMA, TEA, TIBA) ou MAO antes da fixação do complexo metalocênico. Compostos como TEA e TIBA reagem com os sítios ácido de Brönsted da superfície do suporte, impedindo a desativação do complexo metalocênico adicionado numa segunda etapa.

A literatura ${ }^{[44-46]}$ tem relatado com freqüência a substituição de MAO no meio de polimerização por trialquilalumínio quando se empregam catalisadores heterogêneos onde o suporte foi pré-tratado com MAO. Nesses casos observou-se também um aumento na atividade catalítica em relação aos pré-tratamentos com compostos alquilalumínio, porém esse comportamento não é observado em alguns suportes ${ }^{[47]}$. É possível
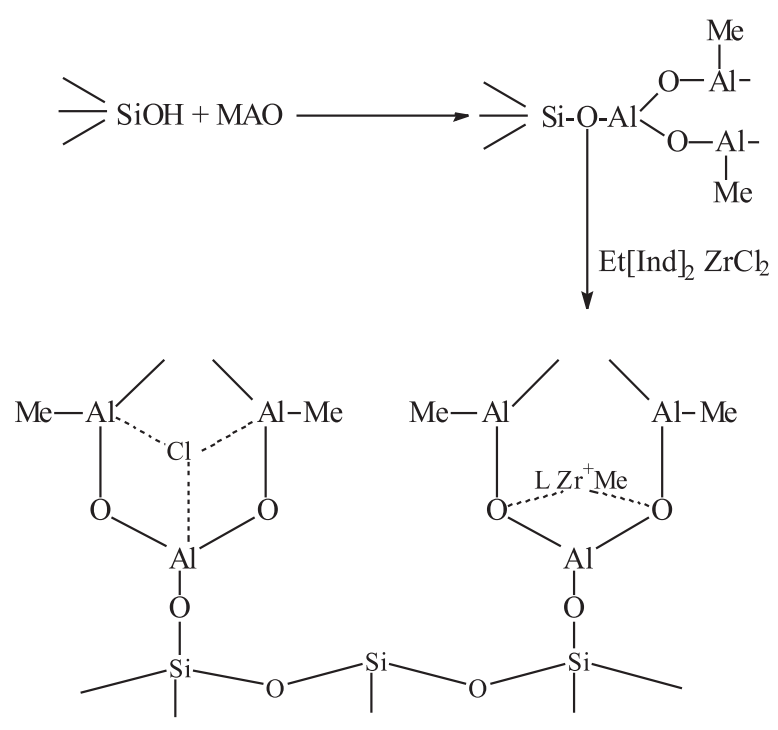

Figura 8. Formação de complexo do tipo coroa na superfície de suportes hidroxilados ${ }^{[25]}$

que a fixação de MAO nas hidroxilas presentes na superfície de certos suportes leve à formação, após a adição do complexo metalocênico, de sítios catalíticos estabilizados, muito semelhantes aos catalisadores homogêneos precursores ${ }^{[25,48,49]}$ (Figura 8). O pré-tratamento com TMA em suportes com umidade controlada tem o objetivo de sintetizar o MAO "in situ" pela reação entre TMA e a umidade contida no suporte. Como a atividade do sistema metaloceno/MAO é proporcional ao grau de oligomerização de MAO, a ordem de adição deve ser aquela onde o sólido úmido é lentamente adicionado a uma solução de $\mathrm{MAO}$, de modo que a reação se passa em condições com deficiência de água e o MAO produzido possui assim maior grau de oligomerização.

\section{Fixação do complexo catiônico}

Sólidos catalíticos preparados por quimissorção do composto metalocênico (com ou sem pré-tratamento) e posterior adsorção de alquilalumínio ou MAO, com formação das espécies cataliticamente ativas na superfície do suporte são chamados de catalisadores de fase única (single-phase catalyst). Esses catalisadores podem também ser obtidos através do contato do complexo ativo (composto metalocênico/MAO), previamente preparado em solução, com o suporte. A adsorção dos componentes do complexo catalítico na superfície do suporte pode ser forçada através do controle da velocidade de evaporação do diluente do sistema ${ }^{[50]}$. A polimerização com esse último sistema catalítico é realizada em um não solvente para o com- 


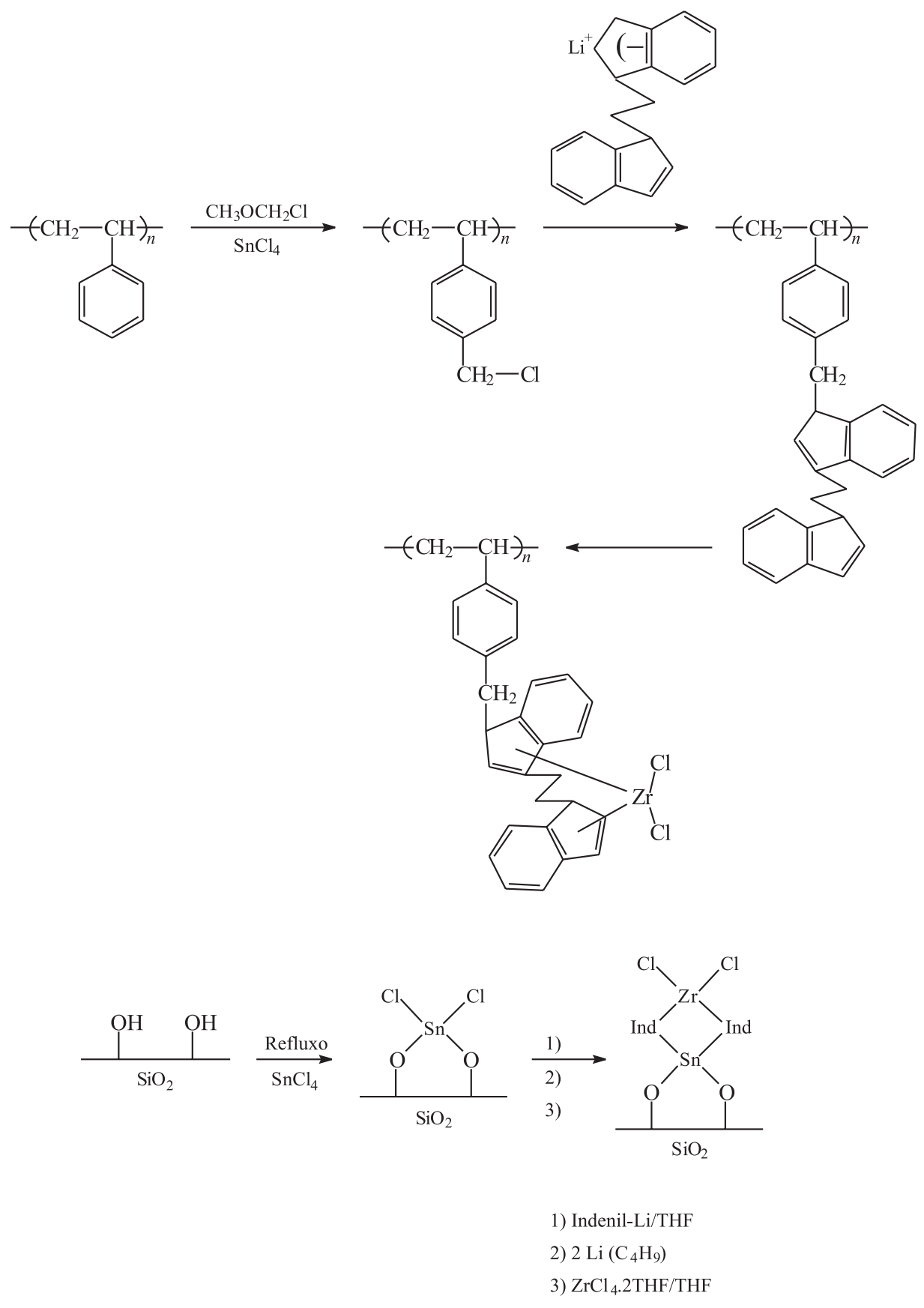

Figura 9. Exemplos de catalisadores metalocênicos suportados por ancoramento ${ }^{[52,55]}$

plexo metalocênico, para evitar a extração do catalisador para o meio de polimerização, ou em fase gasosa. Essa técnica é principalmente encontrada na literatura de patentes industriais.

Nesse sistema catalítico não há necessidade da adição de MAO no meio de polimerização, mas em geral requer adição de um alquilalumínio. Esse tipo de catalisador é menos ativo que o descrito anteriormente, devido à alta sensibilidade da espécie ativa em relação a impurezas.
Ancoramento do composto metalocênico em grupos presentes na superfície do suporte

Neste caso a molécula do metaloceno é sintetizada na superfície do suporte através da reação entre o ligante ou a ponte da futura estrutura do complexo metalocênico com algum grupo acessível presente no suporte (Figura 9) ${ }^{[46,51]}$. Uma reação posterior com tetracloreto de metal de transição leva à formação do complexo metalocênico. Alguns autores sintetizaram catalisadores 
metalocênicos heterogêneos por esse método utilizando tanto suportes inorgânicos ${ }^{[24,51]} \operatorname{como~orgânicos~}^{[52,53]}$ e afirmaram que este tipo de síntese resulta nos catalisadores heterogêneos mais ativos.

\section{Natureza dos suportes}

Alguns sólidos têm sido testados como suportes de catalisadores metalocênicos, entretanto os trabalhos publicados na literatura (principalmente os de patentes) são, em geral, pouco profundos para a compreensão dos fenômenos relacionados à heterogeneização dos catalisadores metalocênicos. Uma explicação para isso é que existe atualmente uma grande competição entre os pesquisadores na busca do suporte e do método mais apropriados para a obtenção de um catalisador metalocênico suportado com melhor desempenho nas polimerizações de olefinas.

Vários compostos metalocênicos quirais e aquirais têm sido heterogeneizados sobre sólidos inorgânicos e orgânicos. Dentre os sólidos inorgânicos ${ }^{[44,45,54-60]}$ pode-se citar a sílica, a alumina ou mistura delas, os alumino-silicatos (zeólitas), compostos de magnésio (cloreto, óxido, fluoreto), fluoreto de cálcio e mesmo o $\mathrm{MAO}^{[61]}$. Os suportes orgânicos foram ainda muito pouco investigados mas, dentre eles pode-se citar resinas à base de estireno com comonômeros que são agentes de reticulação, o polietileno $^{[62]}$, oligo-e polissacarídeos ${ }^{[63]}$.

Soga e colaboradores ${ }^{[54]}$ testaram uma grande variedade de suportes, principalmente os inorgânicos, e afirmaram que quando compostos com características ácidas como alumina e $\mathrm{MgCl}_{2}$ são usados como suporte, os catalisadores resultantes podem ser ativados por trialquilalumínio puro (cloreto de dialquil-alumínio desativa o catalisador), em lugar de MAO. Sílica ou óxido de magnésio não reagem com trialquilalumínio, porém se a sílica for pré-tratada com MAO, atividades relativamente altas são conseguidas mesmo com adição no meio de polimerização de pequena quantidade de MAO ou pela adição de trialquilalumínio. Neste trabalho, Soga relatou ainda que a distribuição de peso molecular dos polímeros resultantes era dependente da cristalinidade dos sólidos empregados como suporte catalítico, isto é, catalisadores obtidos a partir de suportes amorfos (sílica, alumina) originam polímeros com polidispersão estreita enquanto catalisadores suportados em sólidos cristalinos $\left(\mathrm{MgCl}_{2}\right)$ polimerizam formando produtos com larga polidispersão.
Sílica e alumina

Esses óxidos inorgânicos são os sólidos mais estudados como suportes para catalisadores metalocênicos, particularmente a sílica, uma vez que estão disponíveis nas mais variadas faixas de tamanhos de partícula e de distribuição de tamanhos de poros, que são fatores que podem ser controlados durante a síntese do suporte. Outra vantagem do emprego desses sólidos como suporte catalítico é o fato da química da superfície desses sólidos ser razoavelmente bem conhecida ${ }^{[64]}$. Porém, compostos oxigenados não são, em princípio, a melhor escolha para suportar complexos metalocênicos, já que estes podem se coordenar com pares eletrônicos isolados da superfície dos suportes e o que se deseja é manter o metal de transição com o orbital vazio para a coordenação do monômero.

A queda acentuada da atividade dos catalisadores preparados pela fixação direta do complexo metalocênico em sílica ou alumina em comparação com os sistemas catalíticos homogêneos precursores foi explicada como sendo resultado de reações de desativação ${ }^{[65]}$. A composição do composto metalocênico $(\mathrm{Cl} / \mathrm{Zr}=2)$ varia quando ele é suportado em sílica $(\mathrm{Cl} / \mathrm{Zr}<1)^{[50]}$. A presença de sítios ácidos de Brönsted na superfície desses sólidos, grupamentos siloxano ou aloxano, levam a reações de desativação dos compostos metalocênicos pela formação de ligações $\mathrm{Zr}$-O (o par de elétrons isolado do átomo de oxigênio coordena-se com o orbital vazio do zircônio) ou mesmo pode levar à decomposição do complexo metalocênico com liberação dos ligantes. Alguns autores testaram a sílica desidroxilada como suporte e observaram que a baixa acidez de Lewis deste sólido proporcionava baixa afinidade para a fixação do catalisador metalocênico. No caso da alumina foi citada também a ocorrência de cisão da ligação Al-O$\mathrm{Al}$, com formação de espécies inativas $\mathrm{Zr}-\mathrm{O}$ (Figura 10) ${ }^{[66]}$. Somente os sítios ácidos de Lewis favorecem a formação de espécies catiônicas, que podem apresentar um certo grau de atividade para polimerização de etileno se um catalisador metalocênico alquilado for empregado. Essas espécies são ativadas pela adição de cocatalisador.

Por outro lado, os polímeros obtidos com catalisadores suportados em sílica têm, em geral, pesos moleculares, isotaticidade, e temperaturas de fusão superiores aos sintetizados com os catalisadores homogêneos precursores. A diminuição das reações de desativação bimolecular levou a obtenção de síti- 


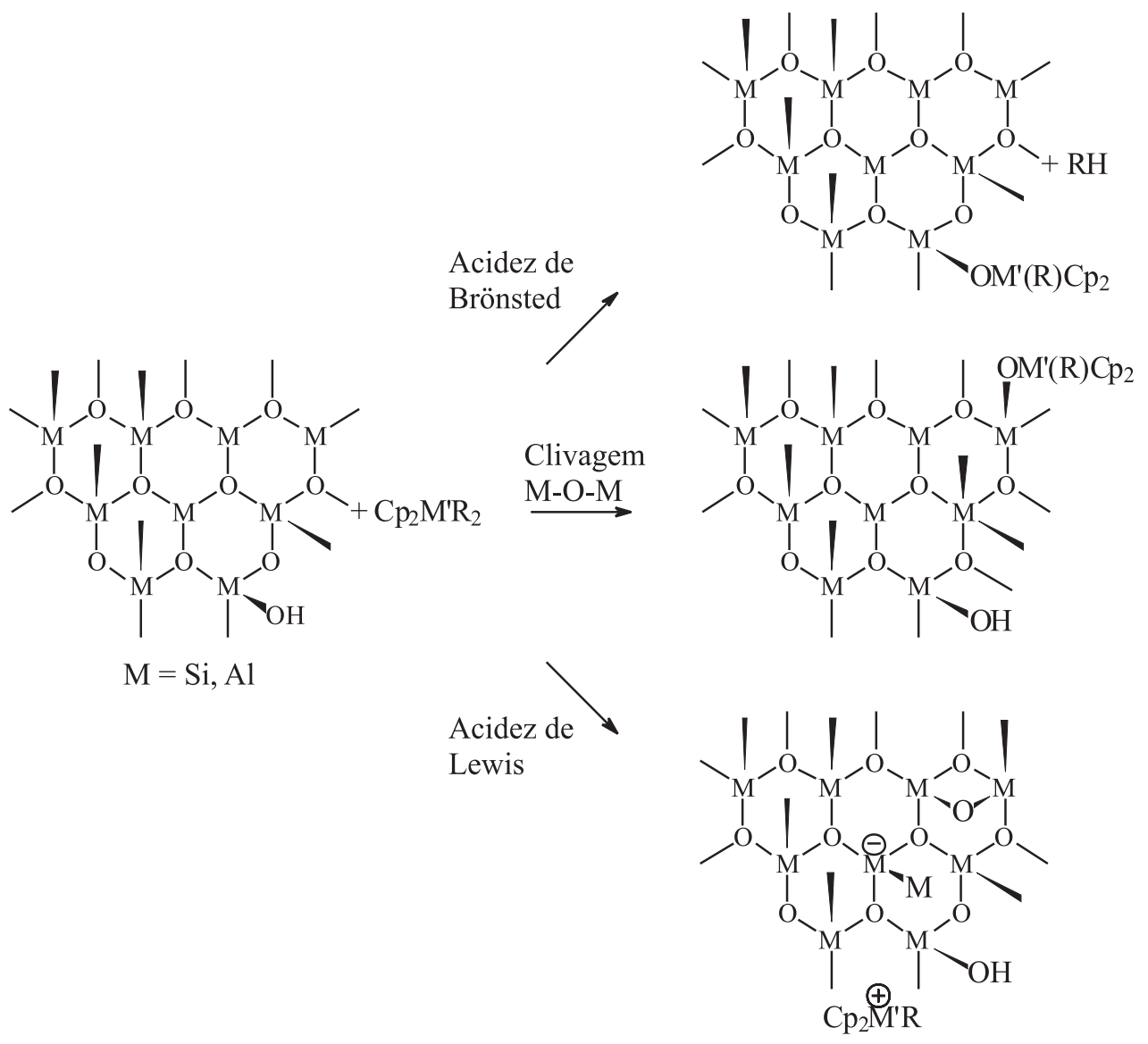

Figura 10. Reações possíveis do complexo metalocênico com a superfície de suportes do tipo óxidos inorgânicos ${ }^{[66]}$

os catalíticos mais estáveis. Além disso, os catalisadores suportados apresentaram alguma atividade mesmo em baixas razões $\mathrm{Al} / \mathrm{Zr}$ ou mesmo sem o uso de cocatalisador, enquanto que os homogêneos correspondentes só funcionam em presença de altas quantidades de MAO. É também relatado na literatu$\mathrm{ra}^{[52]}$ que as polimerizações com catalisadores suportados são mais facilmente reprodutíveis do que as realizadas com os catalisadores homogêneos, cujos resultados são a média de inúmeras polimerizações.

A adsorção de MAO, seguida numa etapa posterior, pela adsorção do composto metalocênico, é atualmente uma das técnicas mais empregadas. A quimissorção de MAO nos sítios ácidos de Brönsted é acompanhada de desprendimento de metano. O prétratamento do suporte com MAO permite a fixação do composto metalocênico com estrutura inalterada $(\mathrm{Cl} / \mathrm{Zr}=2)$. Alguns autores relataram a formação de polímeros com características muito semelhantes aos produzidos com os catalisadores homogêneos. Acredita-se que o composto metalocênico possa migrar através do MAO fixado, formando um sistema com mobilidade semelhante ao homogêneo. Foi também observado que uma quantidade menor de MAO no meio de polimerização era necessária para a ativação desses sistemas suportados uma vez que a desativação bimolecular fica dificultada pela imobilização do complexo metalocênico ${ }^{[52]}$. Até mesmo a substituição de MAO por um alquilalumínio como cocatalisador resultou em atividade catalítica expressiva ${ }^{[65]}$.

\section{Zeólitas}

São alumino-silicatos que apresentam estrutura cristalina altamente ordenada formada pela combinação tridimensional de tetraedros de $\mathrm{TO}_{4}(\mathrm{~T}=\mathrm{Si}, \mathrm{Al})$. Esses tetraedros são ligados uns aos outros por átomos de oxigênio. As zeólitas possuem canais e cavidades de dimensões moleculares cujo diâmetro varia conforme o tipo de zeólita. Quando aquecidas cuidadosamente, as zeólitas podem ser desidratadas sem a perda da sua estrutura cristalina e seus poros ficam acessíveis a outras moléculas. Os vários tipos de zeólitas diferem entre si por sua composição química e pela topologia de sua estrutura. Dentre as zeólitas de poros grandes, as mais comuns são a zeólita Y e a mordenita. 
Devido a presença de átomos de alumínio, a estrutura cristalina das zeólitas apresenta cargas negativas que são contrabalançadas por cátions de compensação do tipo $\mathrm{Na}^{+}, \mathrm{NH}_{4}{ }^{+}, \mathrm{H}^{+}$. Esses cátions têm grande mobilidade e podem ser trocados por outros íons.

Apesar de alguns autores ${ }^{[67,68]}$ afirmarem que compostos metalocênicos são fixados no interior das cavidades das zeólitas, há ainda uma dúvida sobre a localização do sítio ativo de polimerização. O tamanho de poros do material deve ser considerado, uma vez que pode comportar ou não o centro ativo, que estaria então somente na superfície do suporte. Segundo trabalhos realizados no IMA/UFRJ ${ }^{[69-71]}$, outros fatores além deste têm que ser levados em conta para o aumento da atividade. Os catalisadores suportados em zeólitas com altas razões $\mathrm{Si} / \mathrm{Al}$ foram as que apresentaram melhores desempenhos nas polimerizações de olefinas. Esses trabalhos mostraram que atividades catalíticas mais altas são obtidas quando os átomos de alumínio na rede cristalina da zeólita possuem densidade de carga negativa relativamente baixa e sugeriram que o cátion de compensação no átomo de $\mathrm{Al}$ era substituído pelo cátion derivado do composto metalocênico.

\section{$\mathrm{MgCl}_{2}$}

É interessante estudar o comportamento dos catalisadores metalocênicos suportados em $\mathrm{MgCl}_{2}$, uma vez que este material foi considerado o melhor suporte para o catalisador Ziegler-Natta convencional, que constituiu o catalisador de $4^{\mathrm{a}}$ geração $\left(\mathrm{MgCl}_{2} /\right.$ base de Lewis/ $/ \mathrm{TiCl}_{4}$ ). Esse catalisador suportado produz o controle morfológico da partícula de polímero. Na preparação dos catalisadores suportados em $\mathrm{MgCl}_{2}$ a ativação do suporte é o passo mais importante para a obtenção do catalisador com alta atividade. Nessa etapa o $\mathrm{MgCl}_{2}$ anidro se transforma em um suporte amorfo ativo, devido principalmente à redução do tamanho de seus cristais e à formação de vacâncias de cloro na sua superfície, onde o catalisador pode se coordenar.

A ativação do suporte pode ser realizada por dois processos básicos: o método mais utilizado na preparação desse suporte é através da moagem rotacional desse sólido (ativação física), de forma a se obter cristais de tamanho reduzido, que permite a fixação de maiores quantidades de catalisador na matriz cristalina do $\mathrm{MgCl}_{2}$ no processo de impregnação do catalisador no suporte. A adição de base de Lewis (benzoato de etila, por exemplo) durante a moagem se faz necessária para que os cristais de $\mathrm{MgCl}_{2}$ não voltem a se aglomerar (doador de elétrons interno). A moagem como método de ativação do suporte apresenta a vantagem de ser relativamente rápida, de fácil execução e de baixo custo e de produzir catalisadores suportados de alta atividade. Porém o catalisador assim preparado não possui a característica de controle da morfologia da partícula de polímero. Por outro lado, a ativação química permite o controle da forma, densidade e distribuição de tamanhos de partícula do polímero produzido. Consiste na solubilização do $\mathrm{MgCl}_{2}$ e complexação com um doador de elétrons, e a reprecipitação controlada do suporte ativado. A maior desvantagem desse método de ativação é o grande número de etapas necessárias para a preparação do catalisador suportado.

Os catalisadores metalocênicos suportados em $\mathrm{MgCl}_{2}$ possuem alta atividade e produzem, em geral, polímeros com polidispersão larga ${ }^{[48]}$ (em torno de 4), o que indica uma multiplicidade de sítios ativos. Os resultados de copolimerizações mostraram a presença de uma fração de homopolímeros. Empregando-se $\mathrm{MgCl}_{2}$ como suporte de catalisador titanocênico, observou-se que a estabilização da espécie ativa na superfície do suporte resultou num aumento da velocidade de polimerização em relação ao catalisador homogêneo precursor ${ }^{[59]}$. O peso molecular do polímero obtido aumentou, o que mostra que a propagação é mais rápida ou os processos de transferência de cadeia são mais lentos que na catálise homogênea de sistemas titanocênicos.

\section{Suportes orgânicos}

A vantagem do emprego de suportes orgânicos para a heterogeneização dos catalisadores metalocênicos é a possibilidade de se conseguir um melhor controle do tamanho e distribuição de tamanhos de partícula, de manipulação da natureza e distribuição dos grupos funcionais na superfície do suporte e da estrutura principal do sólido através da síntese desse suportes. Suportes poliméricos ${ }^{[52,53]}$ têm sido, ainda que timidamente, empregados na heterogeneização dos catalisadores metalocênicos. Sabe-se que é desejável a presença de alguma funcionalidade superficial controlada nas partículas do suporte polimérico reticulado para que haja maior fixação do catalisador.

Copolímeros à base de estireno-divinilbenzeno são materiais reticulados obtidos por polimerização em suspensão, cujas estruturas porosas apresentam 
características físicas que dependem dos parâmetros reacionais utilizados em sua síntese. De acordo com o teor de agente reticulante e com o sistema diluente utilizados na sua síntese, essas resinas podem ser do tipo gel, gel colapsado ou macroporosas, que são possivelmente as de maior interesse para a imobilização de compostos metalocênicos. A introdução de grupos funcionais na superfície dessas resinas pode ser conseguida com o emprego de um termonômero contendo esse grupo. O uso de resinas com grupos hidroxila ou acetóxi na sua superfície foram citados em literatura de patente ${ }^{[53]}$, mas o desempenho dos catalisadores suportados nesse tipo de resina foi mais baixo do que na resina do mesmo tipo não funcionalizada. Foi desenvolvido um estudo em Tese de Mestrado realizada no IMA/UFRJ sobre a obtenção de polietileno com o sistema metalocênico $\mathrm{Cp}_{2} \mathrm{ZrCl}_{2} /$ metilaluminoxano suportado em resinas esféricas de estireno e divinilbenzeno. Nesta Tese, verificou-se que é possível a obtenção de polietileno com alta atividade catalítica e com propriedades tais como a temperatura de fusão, o grau de cristalinidade e o peso molecular comparáveis (e até superiores) às do sistema homogêneo precursor. Foi observado que a área do suporte orgânico e a preparação do sistema catalítico são de fundamental importância no desempenho do catalisador. Além disso, o polietileno produzido apresentou morfologia que replicou a morfologia do catalisador ${ }^{[72]}$.

\section{Conclusão}

Muito ainda precisa ser estudado na área de catálise via sistema metalocênico, pois muitas e antigas questões continuam sem resposta, como por exemplo: qual a verdadeira função do cocatalisador, qual o mecanismo de polimerização, qual o sistema catalítico adequado à produção em escala industrial, dentre outras. Isso pode ser percebido através do crescente número de patentes que vem sendo depositadas nos últimos anos. Entretanto, a descoberta de uma tecnologia para a preparação de catalisadores metalocênicos heterogeneizados possivelmente será a responsável por outro salto no desenvolvimento dos catalisadores Ziegler-Natta. O desenvolvimento do sistema heterogêneo que permita o controle da morfologia do polímero produzido e, ao mesmo tempo, a adaptação dos sistemas em fase gasosa em operação certamente justificará todo o esforço dispendido, seja ele financeiro ou científico e tecnológico, que tenha como objetivo a descoberta da tecnologia a que se refere. A pesquisa neste campo da Ciência avança a passos largos a cada dia. Este artigo de revisão veio mostrar as diversas faces dos problemas existentes nesta área, e principalmente a variedade de possibilidades de abordagem desses problemas. Portanto, para a elucidação das novas e freqüentes questões que surgem a cada dia, são necessários estudos básicos e sistemáticos.

\section{Referências bibliográficas}

1. Guyot, A., Böhm, L., Sasaki, T., Zucchini, U., Karol, F. \& Hattori, I., "Which industrial polymerization catalysts for the future?", Makromol. Chem., Macromol. Symp. 66, 311-328 (1993).

2. Galimberti, M., Dall'Occo, T., Camurati, I., Piemontesi, F. \& Sartori, F. "New copolymers from metallocenes", Worldwide Metallocene Conference - MetCon'95, Houston, Texas, 1995.

3. Banzi, V., Angiolini, L., Caretti, D. \& Carlini, C. "Elastomeric properties of ethylene/propylene copolymers prepared by zirconocenel methylaluminoxane catalysts", Die Angewandte Makromol. Chem. 229, 113-122 (1995).

4. Kaminsky, W. \& Schlobohm, M. "Elastomers by atactic linkage of a-olefins using soluble Ziegler catalysts", Makromol. Chem., Macromol. Symp. 4, 103-118 (1986).

5. Sasaki, T., Ebara, T. \& Johoji, H, “New materials from new catalysts", Polym. Adv. Tech. 4, 406414 (1993).

6. Stevens, J.C. "Constrained geometry and other single site metallocene polyolefin catalysts: a revolution in olefin polymerization", 11th International Congress on Catalysis - Studies in Surface Science and Catalysis Vol. 101, 1996.

7. Schut, J.H. "The metallocene catalyst ferment continues", Plastic World, maio/1995.

8. Corradini, P. \& Guerra, G. "Stereospecific polymerization processes and stereoregular polymers: our present understanding of mechanisms and structure forty years from the discovery", Polym. Sci. Ser. A 36, $\mathrm{n}^{\circ} 10$, 1324-1340 (1994).

9. Ribeiro Filho, F.A. "Metalocenos: Revolução tecnológica na indústria de polímeros", Palestra proferida na Escola de Química/UFRJ em agosto/1996. 
10. Reddy, S.S. \& Sivaram, S. "Homogeneous metallocene-methylaluminoxane catalyst systems for ethylene polymerization”, Prog. Polym. Sci. 20, 309-367 (1995).

11. Montagna, A.A. \& Floyd, J.C. "Single-sited catalysis leads next polyolefin generation", Hydrocarbon Processing, março/1994.

12. Chien, J.C.W. \& Xu, B. “Olefin copolymerization and olefin/diene terpolymerization with a zirconocenium catalyst system", Makromol. Chem., Rapid Commun. 14, $\mathrm{n}^{\circ}$ 2, 109-114 (1993).

13. Shiomura, T., Asanuma, T. \& Inoue, N. "Inversion of Stereoselectivity in a Metallocene Catalyst", Macromol. Rapid Commun. 17, 9-14 (1996).

14. Pellecchia, C. "Half-metallocene catalysts: structure and polymerization mechanism for the preparation of syndiotactic polystyrene and stereoregular poly(dienes)", International Congress on Metallocene PolymersMetallocenes'95, Bruxelas, Bélgica, 1995.

15. Cramail, H., Dolatkhani, M. \& Deffieux, A. "New EPDMs based on linear dienes: conventional versus metallocene catalysis", Metallocenes'95, Bruxelas, Bélgica, 1995.

16. Ricci, G., Porri, E. \& Giarrusso, A. "Influence of monomer structure on chemo- and stereoselectivity of 1,3-diene polymerization", Macromol. Symp. 89, 383-392 (1995).

17. Sinn, H. \& Kaminsky, W. "Ziegler-Natta catalysis", Adv. in Organom. Chem. 18, 99-149 (1980).

18. Hamielec, A.E. \& Soares, J.B.P. "Polymerization reaction engineering - metallocene catalysts", Prog. Polym. Sci. 21, 651-706 (1996).

19. Lohrenz, J.C.W., Woo, T.K., Fan, L. \& Ziegler, T. "A combined DFT and force field study on the insertion mechanism in Ziegler-Natta catalysis", Polym. Prep. 36, nº 1, 231-32 (1995).

20. Erker, G. "Stereochemistry and catalysis with zirconium complexes", Pure \& Appl. Chem. 63, $\mathrm{n}^{\circ}$ 6, 797-806 (1991).

21. Gupta, V.K., Satish, S. \& Bhardwaj, I.S. "Metallocene complexes of group 4 elements in the polymerization of monoolefins", Rev. Macromol. Chem. Phys. C34 (3), 439-514 (1994).
22. Resconi, L., Bossi, S. \& Abis, L. "Study on the role of methylalumoxane in homogeneous olefin polymerization", Macromolecules 23, 4489-4491 (1990).

23. Brintzinger, H.H., Fisher, D., Mülhaupt, R., Rieger, B. \& Waymouth, R.M. "Stereospecific olefin polymerization with chiral metallocene catalysts", Angew. Chem. Int. Ed. Engl. 34, 11431170 (1995).

24. Ciardelli, F., Altomare, A., Conti, G., Arribas, G., Mendez, B. \& Ismayel, A. "Synthesis and structure of metal complexes with organic polymers or inorganic supports", Macromol. Symp. 80, 29-44 (1994).

25. Chien, J.C.W. \& He, D., "Olefin copolymerization with metallocene catalysts. III. Supported metallocene/Methylaluminoxane catalyst for olefin polymerization", J. Polym. Sci. Part A: Polym. Chem. 29, 1603-1607 (1991).

26. Chien, J.C.W. \& He, D., "Olefin copolymerization with metallocene catalysts. I. Comparison of catalysts", J. Polym. Sci. Part A: Polym. Chem. 29, 1585-1593 (1991).

27. Han, T.K., Choi, H.K., Jeung, D.W., Ko, Y.S. \& Woo, S.I. "Control of molecular weight and molecular weight distribution in ethylene polymerization with metallocene catalysts", Macromol. Chem. Phys. 196, 2637-2647 (1995).

28. Soga, K. e Shiono, T. "Isotactic polymerization of propene with (h-1,1'-ethylenedi-4,5,6,7tetrahydroindenyl)zirconium dichloride combined with methylaluminoxane", Makromol. Chem., Rapid Commun. 8, 305-310 (1987).

29. Antberg, M., Dolle, V., Klein, R., Rohrmann, J., Spaleck, W. \& Winter, A. "Propylene Polymerization by Stereorigid Metallocene Catalysts: Some New Aspects of the Metallocene Structurel Polypropylene Microstructure Correlation", em Proceedings of the International Symposium of Recent Developments in Olefin Polymerization Catalysts, Tóquio (1989).

30. Alt, H.G. "Metallocene Complexes as Homogeneous Catalysts in the Olefin Polymerization", Universität Bayreuth, Palestra proferida no IMA/UFRJ em maio de 1996.

31. Ewen, J.A., Elder, H.J., Jones, R.L., Haspeslagh, L., Atwood, J.L., Bott, S.G. \& Robinson, K. 
"Metallocene/propylene structural relationships: implications on polymerization and stereochemical control mechanisms", Makromol. Chem., Macromol. Symp. 48/49, 253-295 (1991).

32. Alt, H.G. "Metallocene complexes as homogeneous catalysts in olefin polymerization", Russ. Chem. Bull. 44, n 1, 1-8 (1995).

33. Coates, G.W. \& Waymouth, R.M. "Oscillating stereocontrol: a strategy for the synthesis of thermoplastic elastomeric polypropylene", Science 267, 217-219 (1995).

34. Diamond, G.M., Rodewald, S. \& Jordan, R.F. "Synthesis of ansa-metallocenes", Worldwide Metallocene Conference - MetCon' 95, Houston, Texas, 1995.

35. Miyake, S., Okumura, Y. \& Inazawa, S. "Highly isospecific polymerization of propylene with unsymmetrical metallocene catalysts", Macromolecules 28, 3074-3079 (1995).

36. Farina, M. "Old and new problems in polymer stereochemistry", Macromol. Symp. 89, 489-498 (1995).

37. Tian, J. \& Huang, B. “Ethylene polymerization with catalyst systems based on metallocenes with varying steric hindrance and methylaluminoxane", Macromol. Rapid Commun. 15, 923-928 (1994).

38. Aulbach, M., Bachmann, B., Küber, F., Spaleck, W. \& Winter, A. "Metallocenes for isotactic polypropylene - Properties and synthesis", Metallocenes'95, Bruxelas, Bélgica, 1995.

39. Herrmann, H.F. \& Böhm, L.L. "Particle forming process in slurry polymerization of ethylene with homogeneous metallocene catalysts", Polym. Commun. 32, $\mathrm{n}^{\circ}$ 2, 58-61 (1991).

40. Kaminsky, W. "How to reduce the ratio MAO/ metallocene", Macromol. Symp. 97, 78-89 (1995).

41. Langhauser, F., Kerth, J., Kersting, M., Kölle, P., Lilge, D. \& Müller, P. "Propylene polymerization with metallocene catalysts in industrial processes", Die Angew. Makromol. Chem. 223, 155164 (1994).

42. Bonini, F., Fraaije, V. \& Fink, G. "Propylene polymerization through supported metallocenel MAO catalysts: kinetic analysis and modelling",
J. Polym. Sci. Part A: Polym. Chem. 33, 23932402 (1995).

43. Collins, S., Kelly, W.M. \& Holden, D.A., "Polymerization of propylene using supported, chiral, ansametallocene catalysts: production of polypropylene with narrow molecular weight distribution", Macromolecules 25, 1780-1785 (1992).

44. Soga, K. e Kaminaka, M., "Polymerization of propene with the heterogeneous catalyst system $\mathrm{Et}\left[\mathrm{IndH}_{4}\right]_{2} \mathrm{ZrCl}_{2} / \mathrm{MAO} / \mathrm{SiO}_{2}$ combined with trialkylaluminium", Makromol. Chem., Rapid Commun. 13, 221-224 (1992).

45. Kaminaka, M. e Soga, K., "Polymerization of propene with the catalyst systems composed of $\mathrm{Al}_{2} \mathrm{O}_{3}$ - or $\mathrm{MgCl}_{2}$ - supported $\mathrm{Et}\left[\mathrm{IndH}_{4}\right]_{2} \mathrm{ZrCl}_{2}$ and $\mathrm{AlR}_{3}\left(\mathrm{R}=\mathrm{CH}_{3}, \mathrm{C}_{2} \mathrm{H}_{5}\right)$ ", Makromol. Chem., Rapid Commun. 12, 367-372 (1991).

46. Soga, K. e Kaminaka, M., "Copolymerization of olefins with $\mathrm{SiO}_{2}-, \mathrm{Al}_{2} \mathrm{O}_{3}$-, and $\mathrm{MgCl}_{2}$-supported metalloccene catalysts activated by trialkylaluminiums", Macromol. Chem. Phys. 195, 13691379 (1994).

47. Soga, K., Kim, H.J. \& Shiono, T., "Polymerization of propene with highly isospecific $\mathrm{SiO}_{2}$ supported zirconocene catalysts activated with common alkylaluminiums", Macromol. Chem. Phys. 195, 3347-3360 (1994).

48. Marques, M.F.V., Resende, F.C. \& Coutinho, F.M.B., "Estudo do desempenho de catalisadores metalocênicos suportados em zeólita", Anais do $9^{\circ}$ Congresso Brasileiro de Catálise (Trabalhos Técnicos, IBP): 247-297, Águas de Lindóia, SP, 1997.

49. Sacchi, M.C., Zucchi, D., Tritto, I., Locatelli, P. \& Dall'Occo, T., "Silica-supported metallocenes: stereochemical comparison between homogeneous and heterogeneous catalysis", Macromol. Rapid Commun. 16, 581-590 (1995).

50. Patente dinamarquesa $\mathrm{N}^{\circ}$ WO9512622 A1 950511 (1995).

51. Kaminsky, W. \& Renner, F., "High melting polypropenes by silica-supported zirconocene catalysts", Makromol. Chem., Rapid Commun. $14, \mathrm{n}^{\circ} 4,239-243$ (1993).

52. Nishida, H., Uozumi, T., Arai, T. \& Soga, K., "Polystyrene-supported Metallocene Catalysts for Olefin Polymerizations", Macromol. Rapid Commun. 16, 821-830 (1995). 
53. Patente americana US 5.362.824 (1994).

54. Soga, K., Arai, T., Nozawa, H. \&. Uozumi, T., "Recent development in heterogeneous metallocene catalysts", Macromol. Symp. 97, 53-62 (1995).

55. Lee, D-H., Shin, S-Y. \& Lee, D-H., "Ethylene polymerization with metallocene and trimethylaluminum-treated silica", Macromol. Symp. 97, 195-203 (1995).

56. Soga, K., Uozumi, T., Saito, M. \& Shiono, T., "Structure of polypropene and poly(ethylene-copropene) produced with an alumina-supported $\mathrm{CpTiCl}_{3}$ /common alkylaluminium catalyst system", Macromol. Chem. Phys. 195, 15031515 (1994).

57. Tullock, C.W., Mulhaupt, R. \& Ittel, S.D., "Elastomeric polypropylene (ELPP) from alumina-supported bis(mesitylene)titanium catalysts", Makromol. Chem., Rapid Commun. 10, 19-23 (1989).

58. Marques, M.F.V., Coutinho, F.M.B., "Metallocene supported on zeolytes for olefin polymerization", Anais do $36^{\text {th }}$ IUPAC International Symposium on Macromolecules, Seul, Korea, 1996.

59. Satyanarayana, G. \& Sivaram, S., "An unusually stable supported bis(cyclopentadienyl) titanium dichloride-trialkylaluminum catalyst system for ethylene polymerization", Macromolecules 26, 4712-4714 (1993).

60. Soga, K. \& Kaminaka, M., "Polymerization of propene with zirconocene-containing supported catalysts activated by common trialkylaluminiums", Makromol. Chem. 194, 1745-55 (1993).

61. Janiak, C., Rieger, B., Voelkel, R. \& Braun, H.G., "Polymeric aluminoxanes: a possible cocatalytic support material for Ziegler-Natta-type metallocene catalysts", J. Polym. Sci.: Part A: Polym. Chem. 31, 2959-2968 (1993).

62. Patente americana US 4.921.825 (1990).

63. Lee, D-H. \& Yoon, K-B., "Metallocene/MAO polymerization catalysts supported on cyclodextrin", Macromol. Symp. 97, 185-193 (1995).

64. Low, M.J.D., Severdia, A.G. e Chan, J., "Reactive silica. XV. Some properties of solids prepared by the reaction trimethylaluminum with silica", J. Cat. 69, 384-391 (1981).

65. Soga, K. "Highly isospecific, immobilized zirconocene catalysts supported on chemically modified $\mathrm{SiO}_{2}$ ”, Macromol. Symp. 89, 249-258 (1995).

66. Wang, S., Kuntz, B.A., Nistala, S., Collins, S., Harrison, D. \& Coulter, I. "High activity, supported metallocene catalysts for ethylene polymerization and copolymerization", Worldwide Metallocene Conference METCON'95, Houston, Texas, 1995.

67. Ciardelli, F., Altomare, A., Arribas, G. \& Conti, G. "Effect of ligand and inorganic support on polymerization performances of $\mathrm{Ti}$ and $\mathrm{Zr}$ catalyst", Studies in Surface Science and Catalysis, 89, Proceedings of the international symposium on Catalyst Design for Taylor-made polyolefins", Ed. K. Soga e M. Terano, Elsevier (1994).

68. Woo, S.J., Ko, Y.S. \& Han, T.K. “Polymerization of ethylene over metallocenes confined inside the supercage of a NaY zeolyte", Macromol. Rapid Commun. 16, 489 (1995).

69. Marques, M.F.V., Henriques, C.A., Monteiro, J.L., Menezes, S.M.C. \& Coutinho, F.M.B. "Biscyclopentadienyl zirconium dichloride supported on zeolites for ethylene polymerization", Macromol. Chem. Phys. 198, 3709-3717 (1997).

70. Marques, M.F.V., Henriques, C.A., Monteiro, J.L., Menezes, S.M.C. \& Coutinho, F.M.B. "Ethylene polymerization with $\mathrm{Cp}_{2} \mathrm{ZrCl}_{2}$ supported on dealuminated zeolite", Polym. Bull. 39, 567-571 (1997).

71. Marques, M.F.V. \& Coutinho, F.M.B. “Olefin polymerization with supported metallocene on zeolite" VII International Macromolecular Colloquium, Gramado, RS, 1996.

72. Couto Junior, P.A., "Polimerização de etileno com o sistema metalocênico $\mathrm{Cp}_{2} \mathrm{ZrCl}_{2} /$ metilaluminoxano suportado em resinas esféricas de estireno-divinilbenzeno", Tese de Mestrado, Universidade Federal do Rio de Janeiro, 1998.

Recebido: 14/04/97 Aprovado: 02/06/98 